\title{
HACIA UNA TOPOLOGÍA DEL HABLA EL LENGUAJE DE LA DENEGACIÓN SEGÚN DERRIDA
}

\author{
TOWARDS A TOPOLOGY OF SPEAKING \\ DERRIDA'S LANGUAGE OF DENEGATION
}

\author{
JuAn Evaristo Valls BoIx* \\ Universidad de Barcelona
}

Resumen: El presente trabajo aborda la concepción derridiana del lenguaje como topología del habla a través de su lectura de la teología negativa. Esta topología del habla relativiza las posiciones y los límites del discurso y desvela su incompletud e insaturación semántica radicales, mostrándolo permanentemente abierto a la alteridad. Para ello, se expondrá la concepción derridiana de Dios como una desmesura o un significado continuamente diferido. A continuación, se estudiará su relación con el lenguaje a través de la lógica de la denegación. Tal lógica suspende las estructuras del discurso predicativo e invita a valorar el lenguaje como una dinámica de oración y promesa.

Palabras Clave: Alteridad, denegación, Derrida, teología negativa, hospitalidad.

"Becario de investigación predoctoral. Departamento de Filosofía, Facultad de Filosofía. C/ Montalegre, 6, 4 piso, despacho 402308001 Barcelona, valls-boix.j.e@ub.edu. Este trabajo ha sido posible gracias a una ayuda del Subprograma de Formación de Profesorado Universitario (FPU) del Programa Estatal de Promoción del Talento y su Empleabilidad. Una primera versión de este estudio fue presentada bajo el título "Los lugares del habla. Deconstrucción y teología negativa” en el XXI Congreso Valenciano de Filosofía, organizado por la Sociedad de Filosofía del País Valenciano en Castellón de la Plana los días 10, 11 y 12 de marzo de 2016. 
Aвsтract: This paper analyzes Derrida's conception of language as a topology of speaking through his readings of negative theology. This topology of speaking relativizes positions and boundaries of discourse and shows its radical incompleteness and its semantic unsaturation, configuring it as permanently open to alterity. In order to do this, the paper will expose Derrida's conception of God as an excess or a continuously differing sense. Then, the relation between God as alterity of sense and language will be understood as a logic of denegation. This logic cancels the structure of predicative discourse and invites the reader to value language as a dynamics of prayer and promise.

KeYwORDs: Alterity, denegation, Derrida, negative theology, hospitality

El lugar y la Palabra son uno.

Si no existiera el lugar,

(Por toda la eternidad),

no existiría la Palabra.

Angelus Silesius, El peregrino querúbico: II, 205

\section{Introducción}

Tan esquivas y oscuras como agudas y penetrantes, la deconstrucción y la teología negativa han seguido caminos que han querido a menudo observarse como paralelos, incluso comunes. Una retórica escurridiza de la negación y el evitamiento como cualidad principal de ambos, sea para evitar la traición de definir a Dios o para aludir, en cualquiera de las suertes, a esa X denominada trace, escritura o différance, ha llevado a la crítica a menudo a reconocer en Derrida un heredero de la vieja tradición apofática de Dionisio, Eckhart o Silesius. Si bien ya en un texto temprano como el de "La différance" ${ }^{1}$ Derrida distanciaba de la discursividdad propia de la teología negativa el trabajo de la deconstrucción, la tensión y la confusión entre ambos proyectos era patente. Había ya, desde aquella insinuación, el deber de hablar, de explicar la distancia y comprender el espacio que separa a ambos. Había, en definitiva, que hablar de cómo no hablar,

${ }^{1}$ Texto de 1968 recogido en Marges de la philosophie (Derrida, 1972, 1-31). Citado en Derrida, 2003, 149. 
de ese evitamiento del habla que solo puede suceder en el habla misma y que, en cierta forma o bajo cierta lectura, hermana efectivamente la deconstrucción y la teología negativa.

Este deber, esta llamada, ocupó algunos textos de Derrida de los años 80 y 90 como D'un ton apocalyptique adopté naguère en philosophie (1983), Saufle nom (1993d) o Khôra (1993c), así como algunas otras conferencias y ensayos recogidos en Psyché. Inventions de l'autre (vol. II, 2003)². Es quizá la conferencia de 1986 pronunciada en Jerusalén "Comment ne pas parler? Dénégations" (Derrida, 2003, 145-200) la que recoge con mayor fuerza la cuestión que nos ocupará en este trabajo: ¿Cómo hablar del otro, cómo representar la alteridad sin inventarla o perderla? (Derrida, 2003, 170, nota 1) ¿Cómo hacer justicia a lo absolutamente otro en el lenguaje sin caer ni en un trasunto del yo ni en una conjuración de la presencia que se mostraría sin poder expresarse $e^{3}$ ? En definitiva, ¿`ómo hablar sin hablar o decir, sin recurrir al esquema propio del antropomorfismo gramatical o a un orden ontoteológico? ¿Cómo hablar de Dios como se debe?

Así, el propósito de este estudio consiste en mostrar, a través de la lectura derridiana en clave deconstructiva de autores de la teología negativa, una concepción del lenguaje como topología del habla en la que el discurso queda permanentemente abierto a la alteridad, insaturado e incompleto. Ello será posible mediante la concepción de Dios como absoluta alteridad y desmesura o como significado continuamente diferido, que instaurará en el lenguaje una lógica de la denegación allende las estructuras del discurso constatativo o predicativo, y anclada en los elementos de la oración y la promesa, ambos claves de la apofática. El interés de una deconstrucción de la teología negativa para los debates contemporáneos filosóficos y de teoría de la literatura radica en la fecundidad

\footnotetext{
${ }^{2}$ Para lo cual, sin lugar a dudas, fue imprescindible el cambio de la concepción derridiana de dios como principio ontoteológico, sentido y pura presencia últimos a que tiende todo discurso, propio de De la grammatologie (1970) - una comprensión, por lo demás, clásica, que lo haría "indiferente" o poco interesante, en la línea crítica incluso del existencialismo sartriano (Sartre, 1996, 60 ss.) -, a la de Dios como una alteridad, como lo absolutamente diferente, como un significado en retirada, muy compatible con la deconstrucción y propio de un Derrida, digamos, tardío (afín esta vez a Lévinas, por ejemplo en Lévinas, 1974, y, especialmente para la temática que nos ocupa, a Jean-Luc Marion (1991), aunque con importantes desacuerdos en sus implicaciones lingüísticas). Así lo reconoce Derrida en la entrevista "Epoché and Faith" (Sherwood y Hart, 2005, 27-50, particularmente pp. 36-37). Son clarificadores al respecto los breves comentarios de Rosàs Tosas (2012, 319 ss.).

${ }^{3}$ Presente en el Wittgenstein del Tractatus (Wittgenstein, 2003, $\$ \$ 6.522$ y 7), del que Derrida también se distancia $(2003,153)$, al menos de sus interpretaciones habituales.
} 
de este lenguaje de la denegación y esta topología del habla para, de un lado, ofrecer una respuesta postestructuralista al problema heideggeriano de la ontoteología y el olvido del ser, $y$, de otro, comprender o aproximarse a una dilatada y diversa deriva nihilista de la literatura contemporánea (de Artaud a Beckett, de Mallarmé a Plath) y de los discursos de la alteridad que, en un esfuerzo por callar, por silenciarse y por no decir, no pudieron evitar el anonadamiento sino a través de la profusión, del ejercicio de la escritura hasta la extenuación: de hacer hablar al lenguaje hasta hacerlo claudicar, hasta el abandono o el suicidio, en una preocupación por decir ese no, ese hay que no hablar: esa denegación del lenguaje que solo puede ser lingüística, literaria: "Le discours apophatique, une fois analysé dans son type logico-grammatical, nous donne peut-être à penser le devenir-théologique de tout discours" (Derrida, 2003, 148).

\section{Dios, la absoluta alteridad}

Dios es pura nada, no lo tocan ni el ahora ni el aquí. Cuanto más quieras aprehenderlo, más te huirá. Angelus Silesius, El peregrino querúbico: I, 25

Hagamos notar primero el rechazo derridiano de la teología negativa entendida como discurso. En este rechazo de la discursividad se situaría la desavenencia que Derrida ha recalcado frecuentemente con la tradición apofática. Se trata de dos rechazos ligados: en primer lugar, es menester evitar comprender la apofática como un discurso, como la teología negativa, que sistematizaría la negación y haría de ella un mero gesto metafísico, basado quizá en revocar una lógica, pero con vistas a reformarla por otros medios: se trataría de un discurso de la negación basado en una clásica estructura dual metafísica, en una lógica opositiva (Coward and Foshay, 1994, 7). La teología negativa no debería comprenderse, pues, como un discurso predicativo o constatativo en ninguna de sus versiones, como una forma de respetar la magna esencia de Dios corrigiendo las limitaciones de los conceptos de cuño antropomórfico (Derrida, 2003, 150), para proponer una 
reforma terminológica quizá más muda, pero siguiendo el mismo patrón lingüístico. Rechazar esta discursividad implica el segundo rechazo: comprender a Dios como una hiperesencialidad, como una sublime esencia que desborda y revienta los odres lingüísticos, pero que al fin y al cabo es una presencia y un garante de sentido cuya magnitud es inefable: una presencia o significado exultante ante el que la palabra languidece, ante el que cualquier significante es insuficiente, un fenómeno saturado ${ }^{4}$. Esta manera de entender a Dios traicionaría su propia consideración como (estando) más allá del ser o del lenguaje. Conllevaría, de algún modo, detener la lógica apofática en un punto que la contradiría, estableciendo un límite sólido que designaría, digamos, el reino del lenguaje y, extramuros, aquello de lo que no es capaz. Así, una de las consecuencias misticistas de este esquema consiste en entender a Dios como magna presencia inefable: la supuesta elevación o rarefacción del discurso apofático, que partiría de la negación de todos los discursos teológicos hasta la plena supresión del lenguaje, donde se produciría la unión muda con lo inexpresable, con la pura presencia que solo puede verse o mostrarse, como apuntaría el primer Wittgenstein. Ello entendería el silencio como opuesto al lenguaje y le conferiría, tanto como a la oración, la capacidad plena de unión o comunión con Dios.

La clave de estos dos rechazos es que a ellos subyace una misma estructura ontoteológica que entiende el ser a través del lenguaje, que concibe el ser como una presencia completa y cerrada a la que el lenguaje designa y refiere, capta, aprehende o coge, en fin, dice. Así, comprendida como discurso o asunción de superesencialidad (Derrida, 2003, 152), la teología negativa se reduce a un gesto pobre, a una retórica enrevesada hueca. A una versión difícil de la teología catafática que la negaría siguiendo su misma lógica, repitiéndola por otros medios.

De este modo, se trata de superar el problema de concebir a Dios como un ser más allá del ser a través de su comprensión como lo absolutamente diferente, como lo absolutamente otro5: "Dime, ¿cuál es la diferencia entre yo y Dios?/

\footnotetext{
${ }^{4}$ Así podría entenderse la concepción de Marion. (Rosàs Tosas, 2012, 319). Véase Marion 2000.

5 Taylor indica con agudeza que esta comprensión de Dios como lo absolutamente diferente está ya en Johannes Climacus (una de las otras voces de Kierkegaard). Véase Taylor, 1994, 600: "As such, God is what Kierkegaard sometimes describes as "the absolutely different" [det Absolut-Forskjellige], 'an infinite and qualitative difference' [en unendelig Qualitets-Forskjel] or 'qualitative heterogeneity' [qvalitative Ueensartethed]. Infinite, absolute difference or qualitative heterogeneity is not a difference that is the opposite of identity or sameness but is a more radical difference that cannot be comprehended by any dialectical or binary structure.
} 
No es, para decirlo con una palabra, sino la alteridad" (Silesius, 2005, II, 201). Esta alteridad se sitúa más allá de la lógica predicativa o de la dialéctica binaria, pues ambos dispositivos forman parte de un lenguaje configurador de la identidad y la mismidad. Dios se sitúa más allá, es un más allá, el "hyper", el "más", la excedencia o la desmesura. Dios es el "plus d'être", a la vez más que el ser y no más ser. Dios es el "sin" (sans) que indica sobrepasamiento y abandono, que deconstruye el antropomorfismo gramatical: "Dios es bueno sin bondad, sabio sin sabiduría" (Derrida, 2003, 151). Su lugar es otro que el del lenguaje, es un significado continuamente, absolutamente diferido. Así, Dios niega el binarismo excediéndolo, rechaza la negación, la des-niega. Es decir: Dios habitaría toda negación del lenguaje, todo vaciamiento del lenguaje de sí mismo, toda destrucción del lenguaje, pero la habitaría en negativo: en el vaciamiento del lenguaje, que es lenguaje, tampoco hay Dios. Está más allá. Dios es una denegación del lenguaje, al que este alude negándose, pero por aludirle, Dios ya está más allá:

Le nom de Dieu conviendrait à tout ce qui ne se laisse aborder, approcher, désigner que de façon indirecte et négative. Toute phrase négative serait déjà hantée par Dieu ou par le nom de Dieu, la distinction entre Dieu et le nom de Dieu ouvrant l'espace même de cette énigme. S'il y a un travail de la négativité dans le discours et dans la prédication, il produirait de la divinité. [...] Dieu serait la vérité de toute négativité. [...] "Dieu" nommerait ce sans quoi l'on ne saurait rendre compte d'aucune négativité. (Derrida, 2003, 148)

Así, no es cuestión de anular el lenguaje, sino de comprenderlo como habitado por Dios, como producido por Dios: como ese significante excesivo que busca o llama -volveremos sobre esta llamada- una alteridad que siempre excede la llamada, una promesa anterior al lenguaje, un deber de hablar anterior al lenguaje que no puede sino estar inscrito, ser lenguaje. Llamar o invocar a Dios, orar, instaura un lenguaje de la denegación: un lenguaje que afirma la negación, que dice hay que no hablar, o sea el hay que no: "Denegation [...] is a negation that denies itself and, by so doing, repeats the negation it apparently negates. To denegate is to unnegate, but unnegation is itself a form of negation. More

This difference, which is different from but not opposed to other differences and identities, is absolutely singular". 
precisely, denegation is an unnegation that affirms rather than negates negation." (Taylor, 1994, 596). Se extiende en este "deber no", en decir que no hay nada que decir, en conformar el silencio como un pliegue de las palabras.

De aquí el double bind del título del texto de Derrida, "comment ne pas parler?" o "how to avoid speaking?": La teología negativa pretende mostrarnos cómo no se debe hablar, cómo hay que evitar hablar de Dios si acaso se pretende alcanzar la comunión con él, cómo nos hemos de vaciar de todo lenguaje y todo ser, tender hacia la nada, hacia el desierto, para alcanzar a Dios. Cómo no se debe hablar de Dios como un ser, como un algo:

¿Dónde se encuentra mi morada? Donde no hay ni yo ni tú.

¿Dónde está el fin último hacia el cual debo tender?

Donde no se encuentra ningún fin. ¿Hacia dónde debo ir?

Más allá de Dios, al desierto.

(Silesius, 2005, I, 7) ${ }^{6}$

Es un movimiento hacia la alteridad que, evitando inventarla y proyectarse en ella, aboga por la destrucción del lenguaje y de la identidad para no traicionar a Dios, para no blasfemar y caer en la inexactitud. Es un evitamiento del discurso, del lenguaje predicativo y del atributo:

Si llamase a Dios un ser estaría hablando con tanta falsedad como si dijese del sol que es pálido o negro. Dios no es ni esto ni aquello. Y un maestro dice: aquel que cree que ha conocido a Dios y que conocerá alguna otra cosa, no conocerá a Dios. Pero al decir yo que Dios no era un ser y que estaba por encima del ser, no por eso le he discutido el ser, por el contrario, le he atribuido un ser más elevado. (Eckhart, "Quasi stella matutina", cit. en Derrida, 2011, 16-17)

\footnotetext{
${ }^{6}$ El tropo del desierto, un elemento clásico en la literatura mística y en la teología negativa, es comprendido por Derrida como "une figure paradoxale de l'aporie" (1993d, 52).
} 
La teología negativa nos incita al silencio, a callar, a orar en lugar de alabar (p. ej., Silesius, 2005, V, 162), a llamar a Dios sin describirlo. Pero este silencio está igualmente inscrito en la estructura de la huella, es un silencio en el lenguaje, o el lenguaje silenciando una lógica que le es inherente y de la que no puede desprenderse. El rechazo del lenguaje tiene lugar en el lenguaje, es una denegación. La oración, aunque no predicativa, tiene lugar en el lenguaje. El lenguaje es el lugar. Sin él, no cabría la promesa de Dios, su anulación plena implicaría entender la oración como una comunión directa e inmediata con Dios:

S'il y avait une expérience purement pure de la prière, aurait-on besoin de la religion et des théologies, affirmatives ou négatives? Aurait-on besoin d'un supplément de prière? Mais s'il n'y avait pas de supplément, si la citation ne pliait pas la prière, si la prière ne pliait pas, ne se pliait pas à l'écriture, une théiologie serait-elle possible ? Une théologie serait-elle posible? (Derrida, 2003, 200)

Este es el segundo sentido del título, un sentido de protesta cercano al " $i p e r o$ cómo!", al “¡cómo no!": no se puede dejar de hablar, no hay fenómeno que no esté inscrito, lingüistificado, enraizado en la escritura y la huella (Suciu, 2012, 53): ¿cómo evitar hablar? ¿Cómo dejar de hacerlo? No se puede dejar de hacerlo, de habitar el lenguaje. El lenguaje de la denegación, un lenguaje de o hacia Dios dice justamente ese hay que no hablar, dice el silencio guardado (Derrida, 1999, 109). Hay que decir la no-manifestación. Así el título dice: habría que callarse, pero para callarse hay que hablar. Debemos no hablar, pero este deber está habitando ya el lenguaje:

Le langage a commencé sans nous, en nous, avant nous. C'est ce que la théologie appelle Dieu et il faut, il aura fallu parler. Ce "il faut" est à la fois la trace d'une nécessité indéniable (autre façon de dire qu’on ne peut éviter de la dénier : on ne peut que la dénier) et d'une injonction passée. Toujours déjà passé, donc sans présent passé. Il a bien fallu pouvoir parler pour laisser venir la question “comment ne pas parler ?” (Derrida, 2003, 169) 
Ante la constante retirada de Dios, ante su absoluta alteridad como significado en continuo diferir, el lenguaje no desaparece, sino que se vacía. El discurso no tiende a su rarefacción, sino que prolifera, habla de más, se extiende como significante ante un significado que siempre dice "no todavía" (pas encore) (Derrida, 1985a, 113-14), que ni acontece ni desaparece, sino que es convocado continuamente por un significante que funciona sin él como su promesa, promesa que nunca se cumple ni se revoca, que es promesa siempre en la forma del aplazamiento. Ante esta promesa, el lenguaje persiste como una llamada ${ }^{7}$. Así lo escribe Silesius: "Desnudo no puedo presentarme delante de Dios. Con todo, desvestido/He de entrar en el reino de los cielos, porque en él no se admite lo extraño." (2005, I, 297)

\section{Promesa y oración}

Derrida ofrece una relación novedosa entre significante y significado a través de su pensamiento de esta absoluta alteridad. El texto queda reducido a estilo, a un significante que no requiere del significado para funcionar, sino que está configurado para hacerlo en la ausencia del significado, en su suplencia (Derrida, 1972, 10 y ss) y en su espera. Funciona como si hubiera presencia, pero esta nunca llega. Es un significante excesivo ante un significado diferido, que siempre llega como una sustitución por otro significante, que siempre se aplaza, que solo se revela como guardado, como custodiado por un guardián. Y sin embargo, ni la deconstrucción ni la teología negativa son una mera retórica nihilizante, una

\footnotetext{
${ }^{7}$ En este punto resulta muy ilustrativo el comentario de Derrida al cuento de Kafka "Ante la ley" (Vor dem Gesetz) (Derrida, 1985a), que observa, de un lado, el carácter topológico del título y, de otro, cómo la puerta de la ley está custodiada por un guardián, y detrás de esa puerta habrá otra puerta con otro guardián, siendo la ley lo que está guardado o custodiado, haciéndose solo manifiesta por esta custodia y sin comparecer jamás (o compareciendo notodavía): hay la no-manifestación. Asimismo, las reflexiones derridianas sobre la denegación del secreto en la conferencia de 1986 -cuya relevancia solo señalamos por limitaciones de espacio precisamente- enlazan con este texto y la consideración de la literatura como una religion sans religion en Donner la mort (Derrida, 1999, 173 ss.) (véase la primera parte de Caputo, 1997, "The Apophatic") y la aporía del perdón. Remitimos, para la cuestión del secreto, a Michaud, 2006. Por todo ello, Taylor observa acertadamente que "in an effort to indicate a difference that can be comprehended neither by Hegel's both/and nor by Kierkegaard's either/or, a/theology is driven beyond the precincts of theology "proper" to the province of literature and literary criticism." (Taylor, 1994, 604). Se dirige al lenguaje que habla por hablar, sin decir, que escapa de sí mismo y no encuentra límites, no tiene reino. Derrida sugiere aquí una vinculación de la literatura con el exilio (1993d, 114).
} 
distracción para evitar hablar. Hablan ciertamente, aunque no hablen de nada, dan su palabra. Dios como alteridad, como significado en retirada, ofrece una promesa de sentido, cuyo cumplimiento procede precisamente de un movimiento de différance y consiste en su propio aplazamiento (Nault, 1999, 395). De este modo, un lenguaje de la denegación, vaciado o tras vaciarse -tanto como pudiera- de la lógica opositiva y de su carácter constatativo, se muestra esencialmente como promesa y oración. Actúa como si la promesa fuera realizable. Cuando deja de ser constatativo, cuando deja atrás sus pretensiones de significar o aprehender una referencia o un sentido como presencia que lo fundaría, revela una posibilidad de la palabra anterior a cualquier predicación o constatación: que el significante funciona como promesa de sentido, pero que en cuanto tal es independiente de cualquier sentido o significado: no reclama la presencia, solo la promete y la aplaza continuamente mediante la sustitución, la suple o suplementa con otro significante, de forma que se codifica en la completa ausencia de estos. El lenguaje es el lugar de una promesa, pero solo la cumple con su dilación: "Parler pour (ne) rien dire, ce n'est pas ne pas parler. Surtout, ce n'est pas ne parler à personne. » (Derrida, 2003, 147) ${ }^{8}$. El significado solo puede presentarse en el lenguaje, es decir, no puede ser presencia: solo contamos con su noticia, con su mensajero, con su palabra dada.

La promesa de sentido no se cumple gracias a la presencia de significado, sino al revés: la presencia de significado puede anunciarse gracias a la promesa continuamente aplazada del significante, que funciona en la plena ausencia de aquella y hace posible todo discurso sobre la presencia:

Il y a nécessairement de l'engagement ou de la promesse avant même la parole, en tout cas avant un événement discursif comme tel. Celui-ci suppose l'espace ouvert de la promesse. [ ...] Cet engagement, cette parole donnée appartient déjà au temps de la parole par laquelle, comme en français, je tiens la parole. (Derrida, 2003, 154-156).

\footnotetext{
${ }^{8}$ Lacoue-Labarthe caracteriza justamente la literatura como el discurso del quién, oponiéndola a la filosofía, que abordaría la cuestión del qué (Lacoue-Labarthe, 1988, 156-7). Ello estaría en consonancia con la nota anterior a propósito de los comentarios de Taylor, y, asimismo, con las observaciones del propio Derrida sobre la literatura y la subjetividad como singularidad, ambas entendidas a través del concepto del secreto. Véase Derrida, 1993b, 70.
} 
Hablamos en un lenguaje representativo universal de una singularidad imposible de representar, que se anula como tal en su singularidad, pero que deja su huella en ese lenguaje universal (Suciu, 2012, 57). Pero siempre que uno cree seguir esa huella y alcanzar el sentido, es de nuevo otro significante, otro guardián, otra figura del ser, otra antropomorfización de Dios, un suplemento de lo mismo. De ahí la insistencia en el "más allá", en el "hyper", pero sin referencia, sin encontrar una esencia mayor o más perfecta, es decir, "sin" de nuevo: negatividad e hiperafirmación.

El texto apofático, ese texto no constatativo que buscaba hablar por hablar, hablar de nada para dirigirse a alguien, guardaba en sí una promesa. Y es por ello, al tiempo, una llamada, un apóstrofe, una oración. Una apelación al otro, a que el otro responda y se presencie, una invocación.

Elle constitue un moment essentiel, elle ajuste l'ascèse discursive, le passage par le désert du discours, l'apparente vacuité référentielle qui n'évitera le mauvais délire et le bavardage qu'en commençant par s'adresser à l'autre, à toi." (Derrida, 2003, 178).

La oración, como la promesa o el deber, se producen al tiempo con anterioridad al lenguaje y en el lenguaje, escapan de la retórica apofática mediante esa misma retórica. Estimula al lenguaje y lo pone en camino, no habla $d e_{s} \operatorname{sino} a$, es un dirigirse, un movimiento, un avance para reclamar la alteridad, el don de la promesa, sin más determinación que la parousia del otro, que su respuesta. Así, la oración muestra la misma aporía que la promesa: ambos se entienden habitualmente como ligados y dependientes de un sentido, de un cumplimiento o de una comparecencia, pero su efecto está producido justamente por la retirada de este significado; ambos funcionan como dispositivos lingüísticos en la falta de esta absoluta alteridad, como si no estuviera, sin que esté, más allá del ser. Su anterioridad al lenguaje es un efecto, ella misma, del lenguaje. Por ello señalaba Derrida el "devenir teológico" de todo discurso: toda habla puede reducirse a un hablar por hablar, a una retórica que, en cuanto que rastro o huella, dona una promesa, augura una sustitución, una venida que es, después de todo, prescindible. Por ello, tras revocar el antropomorfismo gramatical, al lenguaje no le queda 
un mutismo, una inefabilidad: sigue quedando el lenguaje, sigue quedando la no-manifestación, el deber de no decir, el poder no hablar, la denegación.

En este sentido, el lenguaje no encuentra nunca su límite, no tiene límite rígido: no hay fronteras para el significante a partir de las cuales se hallaría, quizá el significado, o la realidad, o, en fin, Dios. Todos estos siendo un continuo aplazamiento, un más allá, una promesa, el lenguaje prolifera en su llamada. No encuentra el vacío de lo indecible en el que acotar su territorio, pues este vacío es él mismo lingüístico. Así, de nuevo, el lenguaje no se limita ni se niega, sino que se deniega: puede no haber límite. ¿Cuándo, entonces, se detiene la generación de significantes? Puesto que no termina, ya que lo que sucedería al fin lingüístico sería de nuevo lenguaje, huella y trazo, el discurso siempre se abandona, desiste, renuncia. El texto acaba cuando el lenguaje claudica, se suspende. Su forma es la de la "desistencia", el abandono [Gelassenheit] ${ }^{10}$. Silesius y Eckhart incitan a desprenderse de todo, a abandonar todo ser, toda posición, para encontrarse, más allá, con Dios ${ }^{11}$. De esta forma, el, digamos, auténtico creyente se constituía como tal, podía alcanzar la promesa de comunión con Dios. El creyente se constituía en su abandono, se formaba en su desconstitución, en su desistir de responder a los deseos mundanos, a su afán de representar a Dios, de querer esto o aquello. Del mismo modo, el lenguaje deniega sus límites y se (des)constituye en su vaciamiento, en su desprendimiento, en su constante prolongarse y salir hacia afuera. Denegar los límites del lenguaje es denegar el lenguaje judicativo de las tesis, de la afirmación-negación, de las posiciones (thesis). Supone desistir, reconocer que no se puede salir del lenguaje, o que siempre se está fuera del lenguaje, prolongándolo. Supone reconocer que el lenguaje no es ya una posición, sino un espacio. Un espacio que se constituye vaciándose (Foshay, 1994, 147-8; Coward y Foshay, 1992, 10). Y también supone que ese espacio no adopta la forma del reino ni del territorio delimitado con fronteras. Ese espacio se extiende a través del errar del exilio (véase Taylor, 1984).

\footnotetext{
${ }^{9}$ Remitimos, para todas las cuestiones que suscita este neologismo, al texto "Désistance", en Derrida 2003, pp.201-238. En Coward y Foshay, 1992 (pp. 10-9) muchas de estas consideraciones se aplican a la subjetividad, entendida como desconstitución.

${ }^{10}$ Esta cuestión, que aquí solo mencionamos, se expone con algo más de detalle en Derrida, $1993 \mathrm{~d}, 100$ ss.

${ }^{11}$ Como en Silesius, 2005 I, 22. Incluso también un abandono más allá de Dios, como en Silesius, 2005 II, 92.
} 


\section{Los lugares del habla}

Borrarse.

Solo en la ausencia de todo signo

se posa el dios.

José Ángel Valente, Al dios del lugar ${ }^{12}$

Sirviéndose de un juego de palabras en alemán, Silesius titula uno de sus dísticos "Der Ort is dass Wort (2005, I, 205), el lugar es la palabra. ¿Qué es este lenguaje vaciado, abandonado, desconstituido? ¿Qué es este lenguaje que ha dejado atrás la dialéctica y el intercambio de tesis, que ya no contiene posiciones sólidas, que, estimulado por una promesa, ha proliferado suspendiendo sus límites? El lenguaje de la denegación, el lenguaje que apela, como la apertura de una promesa a la Alteridad, se (des)constituye como espacio del habla, como experiencia de un lugar, como la posibilidad del tener lugar del otro. Un espacio no posicional, el intersticio entre posiciones, el espaciamiento o el "entre", la quiebra o la grieta del suplemento lingüístico. De este modo, una obra (filosófica o literaria, si acaso hay diferencia) ya no se concibe como la argumentación de una tesis, o la defensa de una posición, ya no se trata ni de un posicionamiento rígido dispuesto a ser confrontado o rebatido, o la representación de algo. Consiste ya no en sostener, sino en configurar un espacio en que la promesa pueda consumarse. Es, antes bien, un "tener lugar", un espacio de habla:

Cet événement toujours présupposé, cet avoir-eu lieu singulier, c'est aussi, pour toute lecture, toute interprétation, toute poétique, toute critique littéraire, ce qu'on appelle couramment l'œuvre : au moins le déjà-là d'une phrase, la trace d'une phrase dont la singularité devrait rester irréductible et la référence indispensable dans un idiome donné. Une trace a eu lieu. (Derrida, 2003, 168)

\footnotetext{
${ }^{12}$ Énfasis mío.
} 
Comprender el lenguaje como un lugar no-posicional, como un espaciamiento, supone concebirlo como continua oportunidad para la respuesta, aparición, presencia de esa alteridad invocada ${ }^{13}$. Para la constante venida de lo otro. Esto es: el lenguaje no es posicional, no es saturable semánticamente, en él hay siempre un punto de fuga, una apertura a otra comprensión o interpretación. El lenguaje como espaciamiento se mueve, es flexible, está más allá de las posiciones y las tesis. La posibilidad de cualquier tesis - posición- descansa en el carácter noposicional del lenguaje. De lo contrario, una sola posición, una sola opinión, lo agotaría $^{14}$. Es un lugar de paso, un lugar inapropiable y de continua expropiación (Derrida, 1993d, 93). El discurso ontológico del lenguaje predicativo y referencial queda reducido a un lugar, siendo toda ontología un ejercicio de escritura de ese lugar, una inscripción (Nault, 1999, 402).

Por ello, ya no es cuestión de decir o no decir, hablar o callar, sino del tener lugar (Derrida, 2003, 167) de la huella, del lenguaje. De abrir un espacio al porvenir, a la alteridad, a lo impensado. De hablar para ofrecer un atrio, un trono o un templo vacío (Eckhart, 2014, 35-6) en que se instale la promesa de la alteridad: "Cuando captamos a Dios en el ser, lo captamos en su atrio, pues el ser es el atrio en el que reside" (cit. en Derrida, 2011, 50). El lenguaje de la denegación se torna una dimensión de apertura, un lugar en que la alteridad puede tener lugar, acontecer: un significado otro, otra lectura o interpretación del texto, un imposible e impensado puede avenirse. Una dimensión de apertura que no es ni el ser ni el fundamento (Derrida, 2003, 197) pero que, en cuanto huella, puede estar habitado, quizá transitado, por Dios: una posibilidad de lo imposible. "Dieu n'est pas simplement son lieu [...] Il est et a lieu mais sans être et sans lieu, sans être son lieu” $(2003,166)$.

\footnotetext{
${ }^{13}$ Derrida dedica varias páginas a rescatar un pensamiento del lugar que se puede encontrar en el Timeo (p. ej., 49a, 50a-d, 52a-b) y que, según Heidegger, el propio Platón habría subyugado a su dialéctica: el tritos genos de la khôra, ese espaciamiento concebido como singularidad impasible que excede las dicotomías visible-invisible, sensible-inteligible, activo-pasivo, situándose más allá de ellas como un receptáculo siempre virgen, siempre disponible. (Derrida, 2003, 173 ss). Esta concepción del espacio habría sido sustituida por la res extensa cartesiana, promocionada en última instancia por el idealismo platónico. Para estas cuestiones, es preciso remitirse al texto que Derrida dedicó al asunto: Derrida, 1993c, en particular pp. 58 y ss. Asimismo, puede resultar útil consultar Arfi, 2012.

${ }^{14}$ Esta aporía, que en el fondo es la aporía de la denegación, está muy próxima a la aporía de la decisión, del testimonio y del perdón, como Derrida señala en 1993d, 32. Para la aporía de la decisión, nos remitimos a Derrida, 2005, 52 ss.
} 
Tal y como la lee Derrida, la vía negativa supondría como operación intelectual, en definitiva, un rechazo o reducción del lenguaje centrado en el sustantivo y en sus atribuciones, estéril y traidor ante la excedencia de la alteridad, a favor de un lenguaje del espacio, entendido como el tener lugar de cualquier acontecimiento. Si Dios está siempre más allá, si es un au-delà, si opera como un significado que se bate en retirada, a la exactitud y precisión del lenguaje le queda una, por así decirlo, economía de la lejanía y la proximidad, un dirigirse a Dios, un preocuparse por estar al lado de Dios, entendido Dios como ese Verbo, esa Palabra que no llegan a decirse o a llenarse. La idea, pues, es concebir el lenguaje en su adverbialidad, en su carácter de proximidad y lejanía a ese Bien sin bondad: "Comme l'adverbe quasi nous sommes à côté du verbe qui est la vérité" (Derrida, 2003, 184), así como el creyente debía estar tan próximo como le fuera posible a Dios, tratar de vaciarse para ser habitado por Dios. Estar al lado, acercarse, ofrecer un espacio, hacer como si. Tal sería quizá la forma de invocar al otro sin inventarlo, de llamarlo sin traicionarlo, de dejarle llegar, en algo así como una ética de la hospitalidad: "Laisser le passage à l'autre, au tout autre, c'est l'hospitalité". (Derrida, 1993d, 102).

De esta manera, todo texto estaría ya desde su inicio habitado por la alteridad, por la posibilidad de su avenir, por la oportunidad de ser otro, de leerse otramente, de espaciarse y extenderse. Todo texto estaría ya, en fin, deconstruido, deconstruyéndose, sin ser la deconstrucción un acto o un ejercicio, ni un método, sino antes bien una experiencia de alteridad, o la posibilidad de esta experiencia, o las fisuras y grietas, los suplementos de un discurso cuya discursividad o solidez estaría siempre en cuestión, alejándose, modificándose:

Avrei dovuto precisare che ciò che avviene, avviene decostruendosi. Non sono io che deconstruisco, è l'esperienza di un mondo, di una cultura, di una tradizione filosófica cui avviene qualcosa che chiamo "decostruzione": qualcosa si decostruisce, non funciona, qualcosa si muove, si sta dislocando, disgiungendo o disaggiustando, e incomincio a prenderne atto; si sta decostruendo e bisogna risponderne (Derrida y Ferraris, 1997, 98)

La deconstrucción como experiencia de lo imposible se define asimismo en Saufle nom: 
Loin d'être une technique méthodique, une procédure possible ou nécessaire, déroulant la loi d'un programme et appliquant des règles, c'est-à-dire déployant des possibilités, la "déconstruction" a souvent été définie comme l'expérience même de la possibilité (impossible) de l'impossible, du plus impossible. (Derrida, 1993d, 31-2)

Queda solo el lugar, la oportunidad, el espacio. El esfuerzo de toda obra por ser cada vez otra, una alteridad tan fecunda como imposible. El esfuerzo o la pasión por errar por la lengua, en un exilio exódico por el desierto hacia quién sabe qué tierra prometida.

\section{Conclusión. Ci falt}

El desafío de nombrar a la alteridad sin inventarla, de hablar sin traicionar, que recorre la teología apofática es examinado por Derrida como una operación lingüística consistente en una reducción o disolución de la ontología, la teología o la religión, en definitiva del lenguaje sustantivo, a un espacio de habla. Para ello, ha sido menester depurar la teología negativa de su carácter discursivo y a Dios de su cualidad hiperesencial para rescatar, de un lado, un lenguaje de la denegación y, de otro, un Dios comprendido como lo absolutamente otro, como desmesura o excedencia. Ello tiene como resultado una comprensión del lenguaje como espaciamiento, como significante excesivo que se prolonga con la motivación de una promesa que se cumple en su aplazamiento, en su suplemento, y que no habla de nada, sino que habla por hablar. Sin decir, se dirige siempre $a$ alguien con el carácter apelativo de una oración, de la continua demanda de una comparecencia que aparece siempre como diferida, en otro significante cada vez. El lenguaje, como espacio, muestra su continua disponibilidad a la alteridad, a lo impensado, a lo imposible, entendido como Dios, un significado diferido, o la posibilidad de una interpretación otra del texto. Este espacio, pues, es un "entre" o un espaciamiento a-posicional e insaturable, cuya condición es adverbial y no sustantiva: cerca o lejos de, al lado de un Verbo siempre más allá, como si se cumpliera. Se trata de una experiencia similar a la de la deconstrucción.

El siguiente paso, el paso más allá, consistiría posiblemente en pensar la afinidad de la literatura con este lenguaje como topología del habla, y, en definitiva, 
el devenir-literario de todo discurso o, quizá, el devenir-teológico de la literatura. Consistiría en desprenderse de los nombres sin caer en el olvido de que, ciertamente, el espacio del lenguaje no puede ser abandonado. Puede, al contrario, recorrerse, errar por la lengua.

\section{Agradecimientos}

Agradezco a las profesoras Laura Llevadot y Virginia Trueba sus consejos para la elaboración final de este trabajo, así como a la profesora Begonya Saez por su seminario sobre "Comment ne pas parler? Dénégations".

\section{Bibliografía}

Primaria

Derrida, Jacques (1970). De la grammatologie. París : Éditions de Minuit.

-(1972). Marges de la philosophie. París: Éditions de Minuit.

-(1983). D’un ton apocalyptique adopté naguère en philosophie. París: Galilée.

-(1985). "Préjugés, devant la loi” en DERrida, Jacques et al., La faculté de juger. París: Éditions de Minuit, pp. 87-141.

-(1993a). La voix et le phénomène. París: PUF.

-(1993b). Passions. París : Galilée.

-(1993c). Khôra. París : Galilée.

-(1993d). Sauf le nom. París : Galilée.

-(1999). Donner la mort. París : Galilée.

-(2003). Psyché. Inventions de l'autre II. París: Galilée.

-(2005). Force de Loi. París: Galilée.

-(2011). Cómo no hablar y otros textos. Barcelona: Anthropos.

Derrida, JacQues y Ferraris, Maurizio (1997). Il gusto del segreto. Roma: Laterza. 


\section{Secundaria}

Almond, Ian (1999). "Negative Theology, Derrida, and the Critique of Presence: A Poststructuralist Reading of Meister Eckhart". The Heythrop Journal Vol. 40/ 2, pp. 150-165.

Arfi, Badredine (2012). "Khôra as the Condition Of Possibility of the Ontological Without

Ontology”. Review of International Studies No. 38, pp. 191-207.

Caputo, John D. (1997). The Prayers and Tears of Jacques Derrida. Religion without Religion. Nueva York: Indiana University Press.

Coward, Harold y Foshay, Toby (eds.) (1992). Derrida and Negative Theology. Nueva York: State University of New York Press.

Chritchley, Simon (2007). Muy poco... Casi nada. Sobre el nibilismo contemporáneo. Barcelona: Marbot.

Foshay, Toby Avard (1994): "Denegation, Nonduality, and Language in Derrida and Dōgen”. Philosophy East and West Vol. 44/3, pp. 543-558.

Haidu, Peter (1990). "The Semiotics of Alterity: A Comparison with Hermeneutics”. New Literary History Vol. 21/ 3, pp. 671-691.

Hart, Kevin (1989). The Trespass of the Sign. Deconstruction, Theology, and Philosophy. Cambridge: Cambridge University Press.

Heidegger, Martin (2013). Identidad y diferencia. Madrid: Anthropos.

Lacoue-Labarthe, Philippe (1988). “The Response of Ulysses". Topoi Vol. 7/2, pp. 155-160.

LÉvinas, Emmanuel (1974). Autrement qu'être. Au-delà de l'essence. La Haye: Martinus Nijhoff.

Llevadot, Laura (2013). Kierkegaard Through Derrida: Toward a Postmetaphysycal Ethics. Aurora CO: The Davies Group Publishers.

Marion, Jean-Luc (1999). "Au nom. Comment ne pas parler de 'théologie négative”. Laval théologique et philosophique Vol. 55/3, pp. 339-363.

-(1991). Dieu sans l'être. París: PUF.

-(2000). “The Saturated Phenomenon”, en Janicaud, Dominique y CouTine, Jean Francois (eds.). Phenomenology and the Theological Turn. The French Debate. Nueva York: Fordham University Press.

Maestro Eckhart (2014). El fruto de la nada. Madrid: Siruela.

Michaud, Ginette (2006). Tenir au secret (Derrida, Blanchot). París: Galilée. 
Muñoz González, Diana María (2014). "Deconstrucción y teología negativa. El juego entre différance y diferencia ontológica”. Estudios filosóficos No. 50, pp. 67-86.

Nault, FrançoIs (1999): "Déconstruction et apophatisme: à propos d'une dénégation de Jacques Derrida". Laval théologique et philosophique Vol. 55/3, pp. 393-411.

Platón (2004). Ión, Timeo, Critias. Madrid: Alianza.

Rampérez, Fernando (2013). "Paul Celan y Jacques Derrida. Errar por la lengua, dejar hablar al tiempo" Tropelías. Revista de Teoría de la Literatura y Literatura Comparada no. 19, pp. 45-59.

Rosàs Tosas, Mar (2012). "Per què no disposem d'un concepte adequat a Déu? Jean-Luc Marion, Jacques Derrida i Mark C. Taylor”. Ars Brevis No. 18, pp. 315324.

Sartre, Jean-Paul (1996). L'existentialisme est un humanisme. París: Gallimard.

Sherwood, Yvonne y Hart, Kevin (eds.) (2005). Derrida and Religion: Other Testaments. Nueva York: Routledge.

Silesius, Angelus (2005). El peregrino querúbico. Madrid: Siruela.

Suciu, Livia G. (2012). "La déconstruction derridienne et les discours qui se confrontent avec l'expérience de la singularité : la théologie négative et la phénoménologie radicale". Journal for Communication and Culture Vol. 2/1, pp. 49-67.

TaYlor, Mark C. (1994). “Denegating God”. Critical Inquiry Vol. 20/4, pp. 592-610.

-(1992). "nO nOt nO”, en Coward, Harold y Foshay, Toby (eds.). Derrida and Negative Theology. Nueva York: State University of New York Press, pp. 167-199.

-(1984). Erring. A Postmodern A/Theology. Chicago: University of Chicago Press.

Westphal, Merold (1995). "Postmodernism and Religious Reflection". International Journal for the Philosophy of Religion No. 38, pp. 127-143.

Wittgenstein, Ludwig (2003). Tractatus logico-philosophicus. Madrid: Alianza.

Wolosky, Shira (1998). “An 'Other' Negative Theology: On Derrida's 'How to Avoid Speaking? Denials”. Poetics Today Vol. 19/2, pp. 261-280.

Wolosky, SHIRA (1995). Language mysticism: the Negative Way of Language in Eliot, Beckett, and Celan. California: Stanford University Press. 
Recibido: 26/05/2016

Aceptado: 14/06/2016

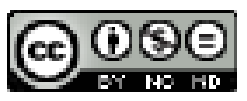

Este trabajo se encuentra bajo una licencia de Creative Commons ReconocimientoNoComercial-SinObraDerivada 4.0 